\title{
Hospitality, professionalism and meaningful work
}

\section{Cheryl Cockburn-Wootten}

\author{
Dr Cheryl Cockburn-Wootten \\ adopts a critical \\ organisational \\ communication perspective in \\ her work to examine issues \\ within tourism and \\ hospitality relating to \\ accessibility, equity and \\ dignity. She aims to facilitate \\ research that informs and \\ makes a difference to our \\ society. As a 'flipped \\ academic', she disseminates \\ research in a variety of \\ creative ways, to reach \\ beyond the confines of \\ academia.
}

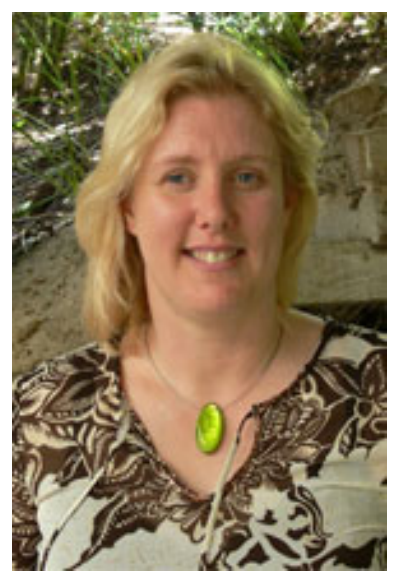

What does it mean to be a professional? What sort of values, knowledge and relationships do we consider essential to become a professional? How does thinking about what professionalism is and could become contribute to the work and organisation of hospitality?

This brief insight will provide a synopsis of a conceptual article that endeavoured to open up our understandings and opportunities for the concept of professionalism within hospitality [1]. The article was a conceptual discussion piece, aiming to critically examine understandings of being professional and what it could become for the hospitality sector. An organisational communication perspective was adopted to highlight how wider social discourses, relationships and language communicate and construct particular ways of being for understanding self, communities and organisations within society. The article also highlights the role of communication to achieve identification for the sector. The hospitality industry has been plagued by negative media attention around the tensions between low pay and finding the right staff with the required skills [1]. Previous research has illustrated that many graduates and prospective employees do not envisage the sector as a legitimate job or long-term career prospect [2]. To reverse these problems, a consideration of the meaning of work and aiming for professionalism in the sector has been identified as one possible solution.

The concept of work can be communicated and interpreted in different ways. Perhaps your first thought of 'work' is that 'it pays the bills and has to be done' - so an element of compulsory drudgery is associated to this first thought. It is fair to say then, that the concept of work can include both negative and positive aspects. Considering the concept more broadly, we can see this negative association is not always the case. The work involved in maintaining and doing certain leisure activities, such as dog training and gardening is not always exclusively negative. Within the concept of work there are certain conditions that negate the negative association. In Cockburn-Wootten's [1] conceptual article, this argument was made to change the association and avoid traditional disciplinary managerial tactics. She discusses previous organisational communication research that has identified that certain workplace cultures develop employees who enjoy their job, gain strong identification and commitment, and feel their work provides meaning and dignity to their lives [3]. The conceptual article argues that a critical communication perspective highlights opportunities to reconsider professionalism for the sector - 
identifying hospitality as meaningful, valued and more than just work.

'Professionalism' is an ambiguous term, but certain principles are always seen as essential in any of its definitions; these include trust, knowledge, ethics and character (ethos) [1]. Professionalism secures certain employment conditions, such as a higher level of autonomy, status in the wider community and collegiality, and importantly, employees regulate themselves to these values. Professionalism provides employees with "a sense of dignity in work, through self-worth, status and meaning" [1]. Communicating the values, practices and qualifications deemed the essential characteristics of a professional are crucial to achieve this sense of meaning for employees [1]. Effective organisational employee training, on-the-job support processes, clear ethical expectations and values need to be embedded to help create identification with the concept of professionalism. All this has typically seen business outcomes such as committed employees, lower turnover rates, and attracting prospective staff with the right skills - all of which contribute to an authentic and excellent hospitality service climate.

To conclude, the article calls for critical consideration about professionalism's contribution to the work and organisation of hospitality. Importantly, to achieve identification with the sector, we need a deeper understanding about the role of communication "to reconstruct individuals" and create meaningful work [1]. Suggestions in the article include a consideration of the how managers facilitate (or not) the workplace culture. Secondly, greater collaboration and dissemination of knowledge, for instance between academics and industry practitioners, would enhance the sector. Rarely does this happen in a reciprocal manner, for example with industry role models working with and within academia [4]. A final note is that being critical aware and reflective, particularly as we educate the next generation of managers, opens us up to the possibilities for ethical transformations that can tackle the current depressing turnover and employment conditions.

Read the original article here: 10.1386/hosp.2.2.215_1

\section{Corresponding author}

Cheryl Cockburn-Wootten can be contacted at: cwootten@waikato.ac.nz

\section{References}

(1) Cockburn-Wootten, C. Critically Unpacking Professionalism in Hospitality: Knowledge, Meaningful Work and Dignity. Hospitality \& Society 2012, 2 (2), 215-230. https://doi.org/10.1386/hosp.2.2.215_1

(2) Gebbels, M.; Pantelidis, I. S.; Goss-Turner, S. Towards a Personology of a Hospitality Professional. Hospitality \& Society 2019, 9 (2), 215-236. https://doi.org/10.1386/hosp.9.2.215_1

(3) Lammers, J. C.; Garcia, M. A. Exploring the Concept of "Profession" for Organizational Communication Research: Institutional Influences in a Veterinary Organization. Management Communication Quarterly 2009, 22 (3), 357-384. https://doi.org/10.1177/0893318908327007

(4) Cockburn-Wootten, C.; McIntosh, A. J.; Smith, K.; Jefferies, S. Communicating across Tourism Silos for Inclusive Sustainable Partnerships. Journal of Sustainable Tourism 2018, 26 (9), 1483-1498. https://doi.org/10.1080/09669582.2018.1476519 